\title{
Medical resources information for the consumer
}

\author{
Helping you make informed decisions
}

by Caryl Gray

T he American health care system has undergone rapid change during the last decade. The rising cost of medical care, along with advances in medical technology, has made it increasingly important for consumers to be well informed about their medical choices. Access to current information also facilitates discussion between physician and patient while making decisions concerning treatment options. The Internet provides a unique opportunity for consumers to have access to current medical information so that they can be active partners in their health care.

This article presents a selected list of Web resources providing health information for the consumer. These resources are starting points for librarians and for the general public searching for health-related information. All of the selected sites publish a disclaimer, which emphasizes the importance of consulting with a qualified health care professional concerning medical and health concerns. The criteria for selection included content, creditability of site sponsor, and currency and authorship of information. Site design was also considered, particularly ease of navigation.

\section{Comprehensive Web sites}

- About.com Health/Fitness. The site is well organized and easy to use. Specific top- ics are listed under broad subject categories such as Alternative/Complementary Health, Disabilities, Diseases/Conditions, Fitness/ Wellness, Mental Health, Recovery/Addiction, and Women's Health. A guide, who is either an expert or has an interest in the topic, has compiled each subject Web page. This site also provides links to scheduled chat sessions on various health topics. Access: http:// home.about.com/health/index.htm?PM= 59_0208_T.

- drkoop.com. C. Everett Koop, former surgeon general of the United States, established drkoop.com. According to Koop, this site "em-

powers consumers to become active, well-in\section{drkoop} formed par-

ticipants to better manage their health." An extensive pull-down menu accesses information on specific "Conditions \& Concerns." Other categories of information include Health News, Family Health, Health Resources, and Health and Fitness. Another resource of interest is "Health Tools," which includes a collection of calculators. These calculators can be used to assess fitness, diet and nutrition, and general health. Calculators to assess the risk for diseases such as

\section{About the author}


heart disease, HIV, and Diabetes Type II are also included. Access. http://www.drkoop.com.

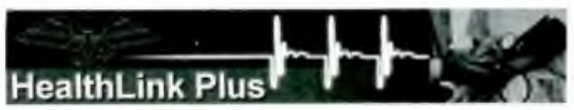

- HealthLink Plus. This consumer health Web site was compiled by the Public Library of Charlotte \& Mecklenburg County (PLCMC) in North Carolina. HealthLink Plus brings together "reliable, recent, and authoritative information from sites selected by PLCMC's professional Information Services staff." The selected resources are categorized by the following headings: General Health Information, Health Care Providers, Health Insurance, Medical Research, Staying Healthy, Mental Health, and Complementary and Alternative Medicine. Each of these headings is linked to a subject page listing appropriate Web resources. The topics associated with each category are also linked, so that specific information can be located easily. For example, the Staying Healthy category lists general wellness, first aid, nutrition, fitness, and stress management as specific topics. This organization makes it easy for a consumer to locate appropriate health information quickly. The site provides access to guidelines for evaluating medical information on the Internet. Access: http://healthlinkplus, org.

- Healthology. This unique Web site offers a different approach to accessing health information. Healthology, Inc., a privately held health media company, offers daily Webcasts. The Webcasts, which address a wide range of health topics, are moderated and e-mail questions can be submitted dur-

ing the discussion. According to the

\section{Healthology} site information: "These Webcasts provide the Internet audience with direct access to the nation's top health experts from institutions around the country." Healthology Live lists the dates and times of future Webcasts. Healthology On-Demand provides access to previous Webcasts. Information on specific subjects can be found at the "Areas of Interest" pull-down menu. These topic pages bring together Webcasts and relevant articles available on the
Healthology site. Access: http:// www.healthology.com/.

- Mayo Clinic Health Oasis. This Web site organizes information by topical centers, such as the Arthritis Center, the Cancer Center, the Children's Center, the Heart Center, the Men's Center, and the Women's Center. Center information sources include recent articles, reference resources, quizzes, and links to other relevant Web sites. New information is added to this site daily. The Interactive Pizza Counter, a unique resource on this site, can be used to create a pizza and to evaluate its nutritional value. The Virtual Cookbook has recipes for a wide variety of healthy dishes, including the Mayo Clinics' recipe for a healthy pizza. Access: http://www. mayohealth.org/.

- MEDLINEplus. The National Library of Medicine provides this health information Web site. "Health Topics" is organized alphabetically by topic with cross-references; topics are also categorized by subject area. Each topic page includes links to information on the disease or condition. For example, the Web page for breast cancer includes links to information on diagnosis, prevention/screening, research, and nutrition. In addition, there is a "Frequently Requested Topics" list for direct access to information on topics of current interest. The site also links to a medical dictionary and to a medical encyclopedia as additional resources for medical information and definitions. MEDLINEplus includes a "Drug Information" section with content provided by the United States Pharmacopeia. More than 9,000 prescription and over-thecounter drugs are described and evaluated. There are also links to information on newly approved drugs and drugs in clinical trial. In addition to the health topics and drug information, this comprehensive site includes a link to MEDLINE, the National Library of Medicine's database. Access: http://www. ncbi.nlm.nih.gov/pubmed/. MEDLINEplus also includes links to addition resources, such as directories of healthcare professionals and a list of medical and health organizations. $A c-$ cess: http://www.nlm.nih.gov/medlineplus/. 
- WebMD. This comprehensive Web site was developed by Healtheon/WebMD to provide access to up-to-clate information for consumers and health care professionals. Access: http://www webmd.com/. Consumers are directed to the WebMD/Health section of this site. Of particular interest is the "Newly Diagnosed" category, which has brief articles on topics such as ADD/ADHD, Alzheimer's, depression, HIV/AIDS, hepatitis C, migraines, and prostate cancer. These articles include links to additional Web-based information and resources about the disease or condition. The WebMD/Health site covers nutrition, fitness, drugs and herbs, and many other topics of interest to the consumer. Access: http:// my.webmd.com/. The "Health Teacher" section of WebMD provides lesson plans and resources appropriate for $\mathrm{K}-12$ health instruction. Access: http://www.healthteacher. com.

-Wellness Web. Conventional Medicine, Alternative/Complementary Medicine, and Nutrition and Fitness are the broad subject sections of this well-organized site. Each section has an editorial board with the membership listed at the top of the section's page. Each editorial board member has a personal

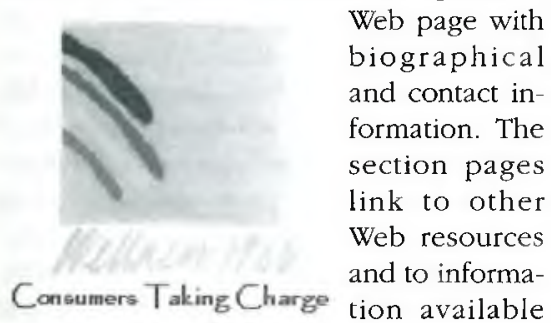
on the Wellness Web. Specific subject information is also listed under "Centers," which include topics such as wellness, fitness, cancer, heart, health insurance, and pain management. "Late Breaking Research" links to the Center for Current Research. The Center searches the National Library of Medicine databases to provide patients with information on current developments at major research facilities. Ongoing additions to this site are listed under "New at WellnessWeb." $A c$ cess: http://wellweb.com.

\section{Academic sites}

- HealthLinks. This site is a project of the University of Washington Health Sciences Center. It brings together Web sites, databases, electronic journals, and other electronic resources related to the health sciences. Access to many of the resources on this site is restricted. A small picture of a lock identifies the restricted resources. An extensive subject index, which includes cross-references, provides access to information on specific topics. Each month this site focuses on a specific topic; for example, October 2000 was devoted to pesticides. Past focus articles can be located at the "Front Page" link. The "Toolkit" section lists resources of interest to specific user groups, including consumers. Access: http://www.hslib.washington.edu/.

\section{AphealthLinks}

- MEDWEB @ Emory University. This site was developed and is maintained by the staff of the Robert W. Woodruff Health Sciences Center Library at Emory University to support the academic and the research programs of the university. The "Consumer Health" section of MEDWEB contains information of interest to the general public. This section contains an extensive list of topics arranged alphabetically; each topic page includes numerous links to related Web resources. Access: http://www.MedWeb.Emory. Edu/MedWeb/.

\section{MEDWEB (a) EMORY UNIVERSITY}

\section{Association Web sites}

Association Web sites provide educational information about particular diseases or conditions, including resources for patients and their caregivers. Non-professional sites also provide opportunities to support financially the advocacy and research missions of the organizations. All sites stress that the information should not be substituted for consultation with a qualified health care professional nor should it be used to self-diagnose a medical problem. This is a very selected list of association Web sites, which contains information of consumer 
interest. The Encyclopedia of Associations is an excellent reference resource for locating information about organizations. Associations Unlimited, a fee-based resource from the Gale Group, is the electronic version of this resource.

\section{Associations (diseases and conditions)}

- Alzheimer's Association. This wellorganized site provides access to information for patients, caregivers, and physicians. The "People with Alzheimer's" page, which provides information on understanding and living with Alzheimer's, is complemented by answers to "Frequently Asked Questions." The "Family Caregivers and Friends" page provides information and support to those providing care to persons diagnosed with Alzheimer's. Access: http://www.alz.org.

- American Cancer Society (ACS). The wealth of material available at the ACS site includes facts about specific types of cancer, information on available treatments (including alternative and complimentary treatments), and advice on prevention and early detection. The "Living with Cancer" page provides answers to general questions about daily living and coping with cancer. The ACS site is complemented by the National Cancer Institute site (see Government sites), which provides more in depth information and links to additional Web resources. Access: http:// www.cancer.org.

- American Diabetes Association. For the newly diagnosed with this disease, the "Diabetes Information" section provides access to useful information. The site also includes advice on nutrition and exercise. Of particular interest is the Virtual Grocery Store, sponsored by commercial producers of lowsugar products, which includes a brief review of basic meal planning for diabetics. Registration is required for full access to the Virtual Grocery Store. Access: http://www. diabetes.org.

- American Heart Association (AHA). The official Web site for the AHA includes information on the warning signs for heart attacks and stroke, risk assessment, exercise programs, and nutrition. The "Heart and Stroke A-Z Guide" is an alphabetical index to information related to these diseases. The link to Books/Cookbooks includes several sample recipes from the AHA cookbooks. Access: http://www.americanheart.org.

- American Stroke Association (division of the American Heart Association). This site, more directly related to stroke than the American Heart Association site, contains a consumer section on risk management, prevention, treatment, and recovery. Information for caregivers and access links to the Stroke Family Support Network provide resources specifically for "stroke families." $A C$ cess: http://www.strokeassociation.org.

- Asthma and Allergy Foundation of America. As well as presenting general information about asthma and allergies, this site contains two sections that users will find helpful. "Ask the Allergist" includes responses to submitted questions, including an archive of past questions. Children can find information appropriate for them in the "Kids and Teens" section. This site also gives local pollen count information. Access: http://www. aafa.org.

- National Multiple Sclerosis Society. This site provides information about the disease for patients and their families. The publications section includes "Just the Facts," which provides factual answers to frequently asked questions. The MS Information section offers "Knowledge is Power," a six-week, free program for those newly diagnosed with MS. Registration is required to receive mailings and newsletters. The Educational Programs section provides access to programs such as "MS Learn on Line" and "Moving Forward." Each program listing provides specific information for accessing the program, including free downloads of software such as RealPlayer. Access: http://www.nmss.org.

MS MULTIPLE SCLEROSIS SOCIETY

\section{Associations (professional)}

- American Medical Association (AMA). "AMA Health Insight" provides access to consumer health resources on the AMA Web site. The site is well organized with clearly defined categories such as "Specific Condition," "General Health," and "Healthy Family." Topics within these categories can be selected from pull-down menus. The site also includes the "JAMA Patient Page," which 
provides information on a current topic of interest. The "Interactive Health" category provides assistance in creating a confidential personal or family health history. Access: http://www.ama-assn.org/consumer.htm.

- American Academy of Pediatrics (AAP). The "You and Your Family" section of this site provides valuable information for parents, including an immunization schedule and car safety information. A link to information about the SIDS (Sudden Infant Death Syndrome) "Back to Sleep" campaign is one of the many resources found in this section of the AAP Web site. The site also includes a list of childcare guides and other association publications of interest to parents. Access: http://www aap.org/family/.

- American Dental Association (ADA). Information for the consumer can be found on the "Public" section of this Web site. "Oral Health Topics A-Z" is the primary location for information on personal and family oral health. The "Frequently Asked Questions" link provides additional information. "Find a Dentist" gives the Internet user access to a list of ADA members to find a local dentist. Directions to the dental office can be printed. The site also provides information on the ADA Seal of Acceptance. Access: http://www.ada.org/.

\section{Government Web sites}

- CDC Web Site. The Centers for Disease Control and Prevention sponsors this well-organized Web site. "Spotlights" links to current information on health-related issues. The "Travelers' Health" section has a wealth of information for the international traveler. Specific health information for geographic regions is available, as are tips for traveling with children and information for travelers with special needs. This section provides links to additional Web resources, such as the U.S. State Department, the National Center for Infectious Diseases, and the World Health Organization, which also provide travel information. The "Health Topics $\mathrm{A}-\mathrm{Z}$ " section indexes the health topics available on the CDC Web site. New information is added to this section on an ongoing basis. Access: http://www.cdc.gov/.

- Food Safety. This site provides comprehensive information on food safety. The "Consumer Advice" category includes general food handling guidelines with additional information for pregnant women, se- niors, and persons with immune diseases. There is also information for specific food products. The "Kids, Teens and Educators" cat-

\section{From Farmito Table} dren on the importance of food safety. These resources include federal government Web sites, federal government/private sector Web sites, and state and local Web sites. This site also includes information on reporting food borne illnesses and product complaints. $A C$ cess: http://www.foodsafety.gov/

- Healthfinder. A service of the Department of Health and Human Services, this wellorganized site serves as "a free gateway to reliable consumer health and human services information." The broad topic areas make information easy to locate. "Hot Topics" puts Web resources on current topics one click away. "Just for You" provides convenient access to resources for specific age or gender groups. Information on minority health and family health are also included in this category. The information listed under each category includes links to Web resources and organizations. Some subjects may include links to electronic journals, databases, and other relevant resources. "More Tools" provides access to additional resources, which can be used to extend a search for health information. Access: http://www.healthfinder.gov/.

- HealthInfoQuest. 'The resources on this Web site are the result of a workshop presented by Maureen Carleton, a medical reference specialist. The outcome of the workshop was a series of pathfinders to be used by public librarians and health information specialists. The Pathfinder Index provides access by topic. Librarians are encouraged to print the pathfinders for their own use as a reference resource or to use them in workshop presentations. Access: http://www.nnlm. nlm.nih.gov/healthinfoquest/

- National Cancer Institute. The "Cancer Information" section of this site provides access to a wealth of information about cancer. "CancerNet" contains information on topics such as types of cancers, treatment options, clinical trials, coping with cancer, and support resources. The Cancer Information Service is a source of current information 
(contact information and the toll-free phone number are listed). This Web site also provides access to the Atlas of Cancer Mortality and to the SEER (Surveillance, Epidemiology \& End Results) Program an "authoritative source of information on cancer incidence and survival in the U.S." Other resources available on the National Cancer Institute Web site include Cancer Trials, Ethnic and Minority Health resources, and links to information provided by the Office of Cancer Complementary and Alternative Medicine. The $\mathrm{Na}$ tional Cancer Institute Web site provides indepth information on cancer research and clini cal trials. Access: http://www.nci nih.gov/.

\section{Other sites of interest}

The Consumer and Patient Health Information Section of the Medical Library Association has compiled an extensive list of evahuated Web resources entitled "Web Sites You Can Trust." This well-organized list is briefly annotated and is an excellent resource for additional consumer health information. Among the resources available on this site is a list of Web resources focusing on children's health and parenting resources. Access: http://caphis.njc.org/consumerAll.html.
- The Melanoma Patients' Information

Page. This non-commercial site provides current information for patients diagnosed with melanoma. The site includes selected readings specific to the stages of melanoma. An "ASK Our RN" link, for submission of e-mail questions to an oncology nurse, was recently added to this site. The "Community" section of this Web site provides access to a bulletin board, a chat room, and other support resources. Access: http://www.mpip.org/

\section{Letter to the editor}

I have just read "Academic librarians as advisors" by Paul Studdard (CERL News, October 2000). Never have I read such a concise and well written defense of, and advertisement for, our profession. People rarely understand what we are professionally capable of, and this piece did much to strongly state our case and our cause.

This is the kind of article that should be featured in all of our professional media. While professions have nothing in the way of apologetics, but this article comes close.-Gary Parsons, Florida Atlantic University,parsons@fau.edu

\section{American \\ Theological Library Association}

It's coming next month ...

\section{ATLASerials}

- The American Theological Library Association's first major digital full-text journal project

- Created for religion scholars by religion scholars

- Digitizing more than fifty (50) essential journals in all theological disciplines, 1949 to present

Take a virtual browse for yourself at bttp://purl.org/CERTR/ATLAS/Pbase1.btml

\section{Get in on this ground floor opportunity and order today!}

Contact Chuck Slagle, ATLAS Sales/Marketing Representative at slagle@atla,com or call toll free (US or Canada) 1-888-665-ATLA

You may also visit our website at http://purl.org/CERTR for continued updates

\section{Visit OUR BOOTH \#634 AT ACRL}




\section{The Campaign for America's Libraries}

\section{Heroes}

@your library"

Libraries across the United States and around the world are embracing the Campaign for America's Libraries. To say thanks, upcoming ads will list the honor roll of libraries and library organizations that have joined the @ your library campaign.

If you are planning to participate, send an e-mail to atyourlibrary@ala.org, fax us at 312-944-8520 or write to the Campaign for America's Libraries, c/o the ALA Public Information Office, 50 East Huron Street, Chicago, $I L 60611$. Please provide a brief description of your plans.

Join us. Be a hero@ your library. 


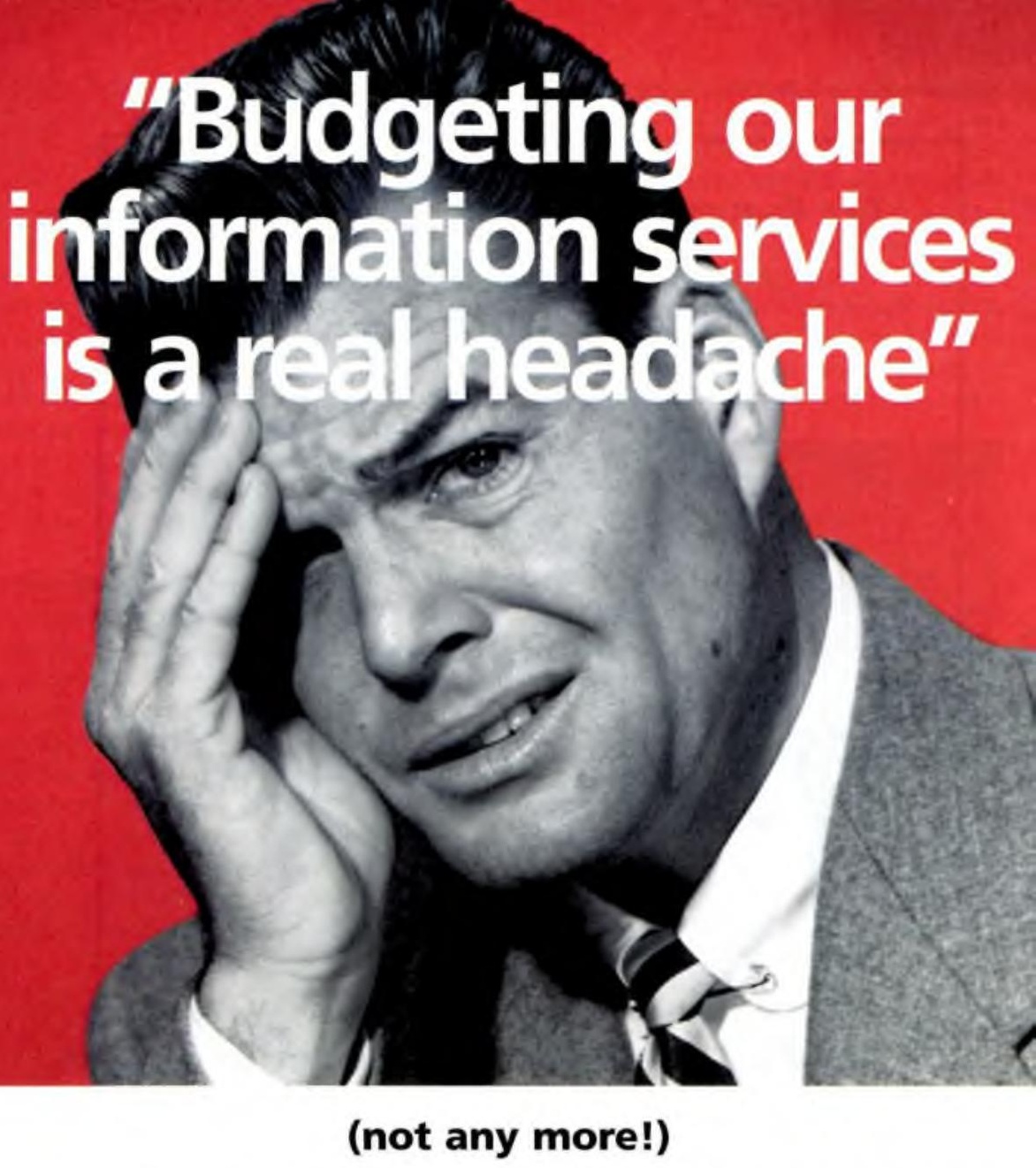

You already know The Dialog Corporation is a world leader in the distribution of information databases. What you might not know, is that "pay as you go" isn't the only way you can subscribe to our service.

To help your budgeting you can now choose a range of database titles on a "fixed-cost, unlimited access" basis. One payment secures 24 hour, 365 day usage with no other charges. Load the database onto your intranet, or access it on the Internet via one of 20 extranet servers.

Whichever way it's delivered, you'll get the advantage of @Site software which allows you to access the database via your favourite browser, and GOLD eDOCS which lets you move from an abstract record to a full text article in seconds.

For more information on our fixed-cost, unlimited access services, contact The Dialog Corporation's OnDisc/@Site Division on +44 (0)1993 899300 (email: ondisc@dialog.com) or your local reseller.

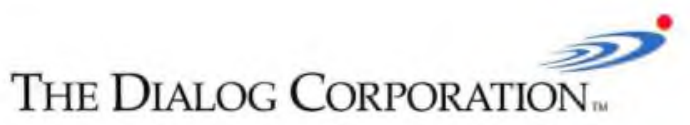

